\title{
The Diagnostic Power of Physical Examination on Surgical Planning for Dialysis Access in Sari Imam Hospital Patients from 2013 to 2014
}

\author{
Hosien Farsavian ${ }^{1 *}$, Mehdi Davoodi ${ }^{1}$, Seyed Jaber Mousavi ${ }^{2}$ and Mehdi Ahangari ${ }^{3}$ \\ ${ }^{1}$ Vascular Surgery, Mazandaran University of Medical Sciences, Sari, Iran \\ ${ }^{2}$ Community medicine, Mazandaran University of Medical Sciences, Sari, Iran
}

${ }^{3}$ General Surgery, Mazandaran University of Medical Sciences, Sari, Iran

\begin{abstract}
Introduction: It is routine to do physical examination to determine the most suitable place for AV access for haemodialysis. Duplex ultrasonography is a high sensitive modality for the evaluation of vessels and can determine vascular diameter. This study was aimed to evaluate the diagnostic power of physical examination for AV access surgical planning in comparison with Duplex ultrasonography (as the gold standard diagnostic tool).

Methods: Physical examination and duplex ultrasonography were done and results were recorded. 117 patients were included on the study. With $95 \%$ confidence interval data were analyzed by SPSS 16.0 and sensitivity and specificity of physical examination were calculated.

Results: Out of 117 patients, in 60 patients (51.3\%), include 33 males and 27 females, physical examination results consistent with Duplex ultrasonography (true positive), with $64.22 \%, 65 \%$ and $86.96 \%$ sensitivity, specificity, and positive predictive value, respectively. AVF failure was significantly more observed in snuffbox (forearm) AVF surgery site.

Conclusion: Preoperative physical examination can be used initially for patients to evaluate a suitable site for AVF surgery. For better AVF outcome, it's suggested to perform duplex ultrasonography study in patients with insufficient clinical findings, 60 years and older, BMI 25-30, diabetes, and hypertension.
\end{abstract}

Keywords: AVF access; Physical examination; Duplex ultrasonography

\section{Introduction}

Providing a proper vascular access for long term hemodialysis in chronic kidney disease patients remains controversial. Physical examination is routine to determine the most suitable AV access for hemodialysis in all these patients [1,2]. Duplex ultrasonography is a safe, noninvasive and high sensitive modality for the evaluation of vessels. It can determine vascular diameter and give an accurate quantitative data about blood flow [3-7]. Preoperative duplex ultrasonography is a gold standard study of veins and arteries to AVFs planning in order that it can result in changes in AVF surgical management, with an increased number of AVFs placed and an improved likelihood of selecting the most functional vessels preoperatively [8-12].

This study was aimed to evaluate the diagnostic power of physical examination for surgical planning in AVF access surgery in comparison with duplex ultrasonography.

\section{Methods}

In this diagnostic study, we have used Duplex ultrasonography as the gold standard diagnostic technique to assess vasculature for planning of dialysis access procedures. Patients with chronic kidney disease who had been candidates for AVF surgery and starting hemodialysis were referred to vascular surgery clinic, Imam Khomeini hospital, Sari, and enrolled in study. This included new cases and those who had nonfunctional AVF. The study approved by ethic committee of Imam Khomeini Hospital. After explanation of study plan and its purposes, verbal consent was taken. Data about all patients included careful history and physical examination for vascular access planning in operating room recorded in patient's data sheet. Physical examination included evaluation of extremities appearance (signs of the presence of scar tissue), assessment and recording of arterial pulses (in a warm environment), length of the vessels and veins bulging and compressibility. Patients assessed by Duplex ultrasonography prior to arteriovenous fistula construction for hemodialysis access with the portable M-Turbo ultrasound system (SN: 03KHZ5 made in USA). Age, sex, BMI, history of diabetes mellitus, cardiovascular diseases and previous surgeries reviewed and recorded. Follow-up visits were done in a week and a month after AVF surgery in vascular surgery clinic, monitoring of the newly placed AV Fistula and palpating for thrill. We used KDOQI Rule of 6's to evaluate the maturity of a recentlyplaced AVF. Fistulas are more likely to be useable when they meet the Rule of $6 \mathrm{~s}$ characteristics 6 weeks after surgery, flow greater than $600 \mathrm{~mL} / \mathrm{min}$, diameter at least $6 \mathrm{~mm}$, no more than $6 \mathrm{~mm}$ deep, and discernible margins. Dialysis session was performed as an assessment after surgery. According to a pilot study was conducted on 21 patients (50\% sensitivity, $20 \%$ specificity), 117 sample size was calculated, with $95 \%$ confidence interval and $15 \%$ error ratio. Patients were divided into four groups depending upon the physical examination and Duplex ultrasonography findings. Patients with consistent Duplex ultrasound

*Corresponding author: Hosien Farsavian, Assistant Professor, Vascular Surgery Mazandaran University of Medical Sciences, Sari, Iran, Tel: +981133044017; E-mail: amir.dadashian@gmail.com

Received November 17, 2016; Accepted December 03, 2016; Published December 12, 2016

Citation: Farsavian H, Davoodi M, Mousavi SJ, Ahangari M (2016) The Diagnostic Power of Physical Examination on Surgical Planning for Dialysis Access in Sari Imam Hospital Patients from 2013 to 2014. J Vasc Med Surg 4: 293. doi: 10.4172/2329-6925.1000293

Copyright: (c) 2016 Farsavian $\mathrm{H}$, et al. This is an open-access article distributed under the terms of the Creative Commons Attribution License, which permits unrestricted use, distribution, and reproduction in any medium, provided the original author and source are credited. 
Citation: Farsavian H, Davoodi M, Mousavi SJ, Ahangari M (2016) The Diagnostic Power of Physical Examination on Surgical Planning for Dialysis Access in Sari Imam Hospital Patients from 2013 to 2014. J Vasc Med Surg 4: 293. doi: 10.4172/2329-6925.1000293

Page 2 of 3

and physical examination plan were considered True Positive. If functional vessels were found on physical examination but did not match with Duplex ultrasonography, results considered False Positive. Unreliable physical examination with proper location identified with ultrasonography was considered False Negative. If neither physical examination nor ultrasonography revealed any significant results, results considered True Negative. $2 \times 2$ table was used to calculate sensitivity and specificity of physical examination, with $95 \%$ confidence interval. SPSS 16.0 windows version was used to analyzing data. $P$ value $<0.05$ was considered statistical significant.

\section{Results}

117 patients were included in this study. 111 patients (95\%) were right hand dominant and 6 patients (5\%) were left hand dominant. 84 patients $(72 \%)$ had vascular access, 76 of them had temporary dialysis catheter (Perm catheter or Shaldone) and 8 patients had a history of vascular access surgery (Table 1 ).

During follow up visits, one week after surgery, 110 patients (94\%) (54 males and 56 females) had proper pulse and thrill. 7 patients $(6 \%)$ had hemodialysis access failure; include 2 males and 5 females.

One month after surgery, 107 patients (91.4\%) (52 males and 55 females) had good pulse and thrill and 10 patients (9.6\%) had hemodialysis access failure (4 males and 6 females).

As primary outcome (a hemodialysis session after vascular access maturation), 107 patients (91.4\%) include 52 males and 55 females had their first session.

In order to determine surgical plan by physical examination, right and left upper extremity were selected in 14 patients (12\%) and 103 patients $(88 \%)$, respectively. To determine surgical plan by Duplex ultrasound, right and left upper extremity were selected in 18 patients $(15.5 \%)$ and 99 patients $(84.5 \%)$, respectively (Table 2 ).

Out of 117 patients, $60(51.3 \%)$ patients had true positive physical examination (33 males and 27 females) whereas 9 patients $(7.7 \%)$ had false positive physical examination ( 6 males and 3 females). 32 patients $(27.3 \%)$ had false negative physical examination ( 9 males and 23 females) while 16 patients (13.7\%) had true negative physical examination ( 8 males and 8 females) (Table 3$)$.

In surgical planning by both physical examination and duplex ultrasound, Snuffbox had the most failures.

\begin{tabular}{|c|c|}
\hline Male & $56(48 \%)$ \\
\hline Female & $61(52 \%)$ \\
\hline Age $10-20$ & $2(1.7 \%)$ \\
\hline $20-40$ & $15(12.8 \%)$ \\
\hline $40-60$ & $39(33.3 \%)$ \\
\hline$>60$ & $61(52.0 \%)$ \\
\hline BMI $<18.5$ & $4(3.4 \%)$ \\
\hline $18.5-24.9$ & $43(37.0 \%)$ \\
\hline $25-29.9$ & $60(51.0 \%)$ \\
\hline $30-34.9$ & $9(7.7 \%)$ \\
\hline $35-39.9$ & $1(0.9 \%)$ \\
\hline$\geq 40$ & $0(0.0 \%)$ \\
\hline DM & $61(52.1 \%)$ \\
\hline CHF & $8(6.8 \%)$ \\
\hline HTN & $76(65.0 \%)$ \\
\hline DLP & $14(12.0 \%)$ \\
\hline
\end{tabular}

Table 1: Patients' characteristics.

\begin{tabular}{|c|c|c|c|}
\hline $\begin{array}{c}\text { By } \\
\text { Ultrasonography } \\
\text { No. (\%) }\end{array}$ & $\begin{array}{c}\text { By Physical } \\
\text { Examination No. (\%) }\end{array}$ & Location & $\begin{array}{l}\text { Surgery Plan } \\
\text { No. (\%) }\end{array}$ \\
\hline $17(14.5 \%)$ & $20(17.0 \%)$ & Snuff box & $17(14.5 \%)$ \\
\hline $4(3.5 \%)$ & $2(1.7 \%)$ & Radiocephalic & $4(3.5 \%)$ \\
\hline $00(0.0 \%)$ & $0(0.0 \%)$ & Ulnarbasilic & $0(0.0 \%)$ \\
\hline $25(21.5 \%)$ & $49(42.0 \%)$ & $\begin{array}{c}\text { Brachio } \\
\text { mediancubital }\end{array}$ & $21(18.0 \%)$ \\
\hline $45(38.5 \%)$ & $0(0.0 \%)$ & Brachiocephalic & $50(43.0 \%)$ \\
\hline \multirow[t]{2}{*}{$2266(22.0 \%)$} & $46(39.0 \%)$ & Unknown & BVT: 10 (9.5\%) \\
\hline & & & AVG: $15(13.0 \%)$ \\
\hline
\end{tabular}

Table 2: Surgery location determined by Physical examination versus Duplex ultrasonography.

\begin{tabular}{|c|c|c|}
\hline & $\%$ & $\mathbf{C l 9 5} \%$ \\
\hline Sensitivity & $65.22 \%$ & $74.16-55.05 \%$ \\
\hline Specificity & $64 \%$ & $79.75-44.52 \%$ \\
\hline Positive predictive value & $86.96 \%$ & $92.98-77.03 \%$ \\
\hline Negative predictive value & 33.33 & $47.46-21.68 \%$ \\
\hline Accuracy & $64.96 \%$ & $73.00-55.96 \%$ \\
\hline Positive Likelihood ratio & $1.81 \%$ & $3.12-1.05 \%$ \\
\hline Negative Likelihood ratio & $0.54 \%$ & $0.82-0.36 \%$ \\
\hline
\end{tabular}

Table 3: sensitivity and specificity of physical examination for AVF surgery site determination.

Physical examination was not very helpful in surgical planning; more commonly in patients aged 60 or over, patients with history of hypertension and BMI range 25-30.

Duplex ultrasound changed surgery planning mostly in patients with history of Diabetes and hypertension. Congestive heart failure and hyperlipidemia had no significant effect on planning or failure (Table 4).

\section{Discussion}

In this study we evaluated the diagnostic power of physical examination for AVF surgical planning. In data analysis the most suitable site evaluated by both clinical evaluation and Duplex ultrasound was left upper extremity (antecubital). 60 patients (51.3\%), 33 males and 27 females, have had consistent physical examination and Duplex ultrasound plan (true positive). Sensitivity and specificity of physical examination for determine AVF surgical plan were $65.22 \%$ and $64 \%$, respectively. The positive predictive value was $86.96 \%$. Patients aged 60 and over, BMI range 25-30 and with Hypertension had more insufficient clinical findings. For this group of patients Duplex ultrasound is required before surgery to improve AVF outcomes. AVF failure rate was not significantly differ based on whether physical examination or duplex ultrasound study.

Smith et al. [13] reported routine preoperative ultrasound vessel imaging do not significantly reduce early failure rates and if clinical evaluation detects anatomy suitable for AVF formation duplex imaging may not be needed. Malvor et al. [14,15] showed AV fistula failure has become more common as more patients are older, have diabetes and/ or vascular disease, so suggested physical examination and ultrasound assessment before surgery in these patients. Although Persic et al. [4] followed 129 patients aged $75 \pm 6$ (65-93) years, and found native AVF can be constructed in the majority of elderly patients, with no significant differences in terms of sex or diabetic status. In a same way, in our study, surgical plan changing and AVF failure was not statistically differ in patients with diabetes, hypertension, congestive heart disease and hyperlipidemia. William et al. [16] observed a higher likelihood of primary fistula failure in women, older patients, and forearm fistulas. 
Citation: Farsavian H, Davoodi M, Mousavi SJ, Ahangari M (2016) The Diagnostic Power of Physical Examination on Surgical Planning for Dialysis Access in Sari Imam Hospital Patients from 2013 to 2014. J Vasc Med Surg 4: 293. doi: 10.4172/2329-6925.1000293

Page 3 of 3

\begin{tabular}{|c|c|c|c|c|}
\hline & $\begin{array}{c}1 \text { week AVF } \\
\text { failure }\end{array}$ & $P$ value & $\begin{array}{c}1 \text { month } \\
\text { AVF failure }\end{array}$ & $P$ value \\
\hline Male & $2(1.7 \%)$ & 0.25 & $4(3.4 \%)$ & 0.42 \\
\hline Female & $5(4.3 \%)$ & & $6(5.1 \%)$ & \\
\hline Age $10-20$ & 0 & 0.36 & 0 & 0.33 \\
\hline $20-40$ & $2(1.7 \%)$ & & $2(1.7 \%)$ & \\
\hline $40-60$ & $3(2.6 \%)$ & & $5(4.3 \%)$ & \\
\hline$>60$ & $2(1.7 \%)$ & & $3(2.6 \%)$ & \\
\hline $\mathrm{BMI}<18.5$ & $0(0.0 \%)$ & 0.45 & 0 & 0.78 \\
\hline $18.5-24.9$ & $1(0.9 \%)$ & & $3(2.6 \%)$ & \\
\hline $25-29.9$ & $6(5.1 \%)$ & & $7(6.0 \%)$ & \\
\hline$\geq 30$ & $0(0.0 \%)$ & & 0 & \\
\hline DM Positive & $4(3.4 \%)$ & 0.54 & $7(6.0 \%)$ & 0.19 \\
\hline Negative & $3(1.6 \%)$ & & $3(2.6 \%)$ & \\
\hline CHF Positive & $0(0.0 \%)$ & 0.45 & 0 & 0.47 \\
\hline Negative & $7(6.0 \%$ & & $10(8.5 \%)$ & \\
\hline HTN Positive & $4(3.4 \%)$ & 0.47 & $5(4.3 \%)$ & 0.24 \\
\hline Negative & $3(2.6 \%)$ & & $5(4.3 \%)$ & \\
\hline DLP Positive & $1(0.9 \%)$ & 0.6 & $1(0.9)$ & 0.65 \\
\hline Negative & $6(5.1 \%)$ & & $9(7.7 \%)$ & \\
\hline \multicolumn{5}{|l|}{ Plan based on $\mathrm{P} / \mathrm{E}$} \\
\hline Snuffbox & $3(2.6 \%)$ & & $5(4.3 \%)$ & \\
\hline $\mathrm{RC}$ & $0(0.0 \%)$ & & $0(0.0 \%)$ & \\
\hline BMC & $3(2.6 \%)$ & 0.24 & $4(3.43 \%)$ & 0.023 \\
\hline unknown & $1(0.9 \%)$ & & $1(0.9 \%)$ & \\
\hline \multicolumn{5}{|l|}{ Plan based on DUS } \\
\hline Snuffbox & $3(2.6 \%)$ & & $4(3.4 \%)$ & \\
\hline $\mathrm{RC}$ & $0(0.0 \%)$ & 0.17 & $1(0.9 \%)$ & 0.04 \\
\hline BMC & $2(1.7 \%)$ & & $3(2.6 \%)$ & \\
\hline $\mathrm{BC}$ & $2(1.7 \%)$ & & $2(1.7 \%)$ & \\
\hline \multicolumn{5}{|l|}{ Surgery plan } \\
\hline Snuffbox & $3(2.6 \%)$ & & $4(3.4 \%)$ & \\
\hline $\mathrm{RC}$ & $0(0.0 \%)$ & & $1(0.9 \%)$ & 0.06 \\
\hline BMC & $1(0.9 \%)$ & 0.19 & $2(1.7 \%)$ & \\
\hline $\mathrm{BC}$ & $3(2.6 \%)$ & & $3(2.6 \%)$ & \\
\hline BVT & $0(0.0 \%)$ & & $0(0.0 \%)$ & \\
\hline
\end{tabular}

\section{Recommendation}

- Preparing proper and warm environment for physical examination and vascular assessment.

- Educating patients how to take care of vascular access.

- Enough time to Physical examination to determine the most suitable AV access.

- Using preoperative duplex ultrasound evaluation for those with ages older than 60 and BMI range 25-30.

- Using preoperative duplex ultrasound evaluation for those with diabetes and hypertension.

\section{References}

1. National Kidney Foundation (2006) Clinical practice guidelines for vascular access 2006 update. Am J Kidney DIS 48: S176-S247.

2. Ilhan G, Esi E, Bozok S, Yurekli I, Ozpak B, et al. (2013) The clinical utility of vascular mapping with Doppler ultrasound prior to arteriovenous fistula construction for hemodialysis access. J Vasc Access 14: 83-88.

3. Edenberg J, Benschop P, Hogasen K (2009) Doppler sonography of arteriovenous fistulas for haemodialysis. Tidsskr Nor Laegeforen 129: 16351638.

4. Persic V, Ponikvar R, Buturović-Ponikvar J (2009) Preoperative ultrasonographic mapping of blood vessels before arteriovenous fistula construction in elderly patients with end-stage renal disease. Ther Apher Dial 4: 334-339.

5. Ferring M, Henderson J, Wilmink A, Smith S (2008) Vascular ultrasound for the pre-operative evaluation prior to arteriovenous fistula formation for haemodialysis: review of the evidence. Nephrol Dial Transplant 23: 1809-1815.

6. Roy-Chaudhury P, Kelly BS, Melhem M, Zhang J, Li J, et al. (2005) Vascular access in hemodialysis: issues, management, and emerging concepts. Cardiol Clin 3: 249-273.

7. Shenoy S (2009) Surgical anatomy of upper arm: what is needed for AVF planning. J Vasc Access 10: 223-232.

8. Robbin ML, Gallichio MH, Deierhoi MH, Young CJ, Weber TM, et al. (2000) US vascular mapping before hemodialysis access placement. Radiol 217: 83-88.

9. Varlaj-Knobloch V, Krnić A, Orsanić-Brcić D, Marinković D (2008) The role of arms color Doppler before creation arteriovenous fistula for hemodialysis. Acta Med Croatica 62: 82-85.

10. Verbeeck N, Prospert F, Mclntyre D, Lamy S (2011) Dialysis arteriovenous fistulas: the critical role of color doppler ultrasound. J Belgian Society Radiol 94: $266-277$

11. Visciano B, Riccio E, De Falco V, Musumeci A, Capuano I, et al. (2014) Complications of native arteriovenous fistula: the role of color Doppler ultrasonography. Ther Apher Dial 18: 155-161.

12. Zamboli P, Calabria M, Camocardi A, Fiorini F, D'Amelio A, et al. (2012 Color-Doppler imaging and arteriovenous fistula: preoperative evaluation and surveillance. G Ital Nefrol 57: S36-S46.

13. Smith GE, Barnes R, Chetter IC (2013) Randomised controlled trial to determine the impact of selective versus routine pre-operative duplex ultrasound scanning in arteriovenous fistula surgery. J Vasc Access 101: 469-474.

14. Malovrh M (2003) The role of sonography in the planning of arteriovenous fistulas for hemodialysis. Semin Dial 16: 299-303.

15. Malovrh M (2011) How to increase the use of native arteriovenous fistulae for haemodialysis. J Vasc Access 32: 53-65.

16. Peterson JW, Barker J, Allon M: Disparities in fistula maturation persist despite preoperative vascular mapping. Clin J Am Soc Nephrol 3: 437-441.

to evaluate a suitable site for AVF surgery. Patients with insufficient clinical findings aged 60 and over and had BMI range 25-30, diabetes and hypertension. For this group of patients duplex ultrasound is suggested before surgery to improve AVF outcomes. Surgical plan changing and AVF failure mostly observed in patients with diabetes and hypertension, but it was not statistically significant. Patients with snuffbox (forearm) as surgery site had the most failure during first week and first month follow up visits. 